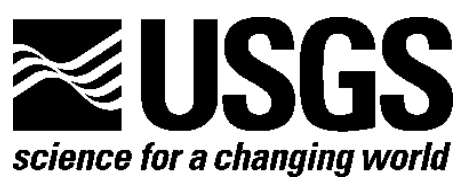

\title{
Methodology for Assessing Quantities of Water and Proppant Injection, and Water Production Associated with Development of Continuous Petroleum Accumulations
}

\author{
By Seth S. Haines
}

Open File Report 2015-1117

U.S. Department of the Interior

U.S. Geological Survey 


\section{U.S. Department of the Interior \\ SALLY JEWELL, Secretary}

\section{U.S. Geological Survey \\ Suzette M. Kimball, Acting Director}

U.S. Geological Survey, Reston, Virginia: 2015

For more information on the USGS-the Federal source for science about the Earth,

its natural and living resources, natural hazards, and the environment-visit

http://www.usgs.gov or call 1-888-ASK-USGS

For an overview of USGS information products, including maps, imagery, and publications, visit http://www.usgs.gov/pubprod

To order this and other USGS information products, visit http://store.usgs.gov

Suggested citation:

Haines, S.S., 2015, Methodology for assessing quantities of water and proppant injection, and water production associated with development of continuous petroleum accumulations: U.S. Geological Survey Open-File Report 2015-1117, 18 p., http://dx.doi.org/10.3133//ofr20151117.

ISSN 2331-1258 (online)

Any use of trade, firm, or product names is for descriptive purposes only and does not imply endorsement by the U.S. Government.

Although this information product, for the most part, is in the public domain, it also may contain copyrighted materials as noted in the text. Permission to reproduce copyrighted items must be secured from the copyright owner. 


\section{Contents}

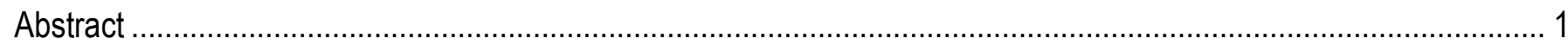

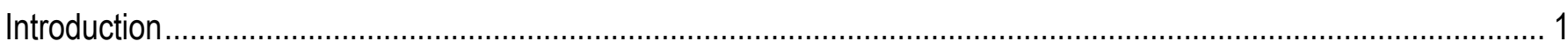

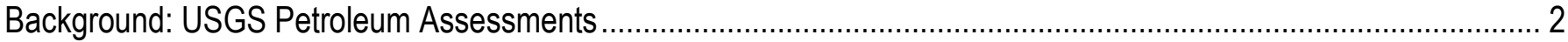

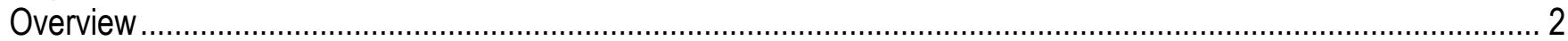

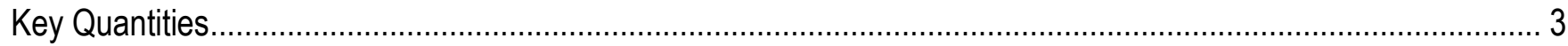

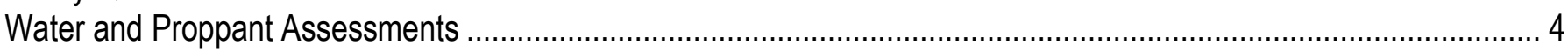

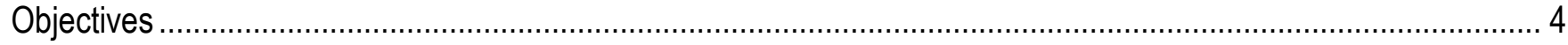

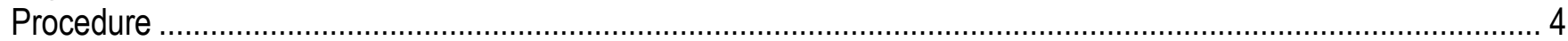

Assessment Considerations and Presentation of Results.......................................................................... 4

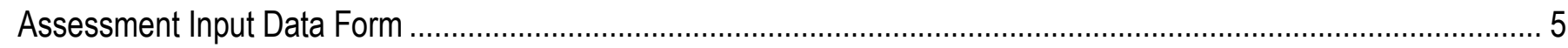

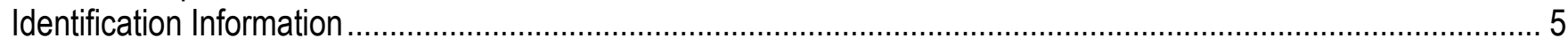

Information from the Associated Petroleum Assessment.......................................................................... 5

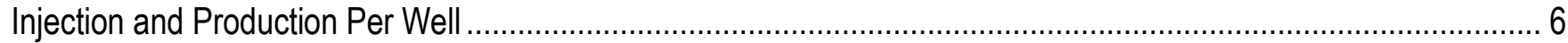

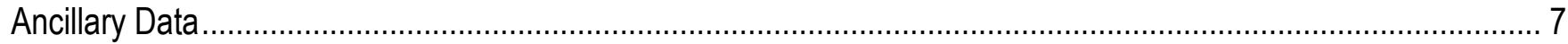

Allocations to other Geographic Entities .................................................................................................

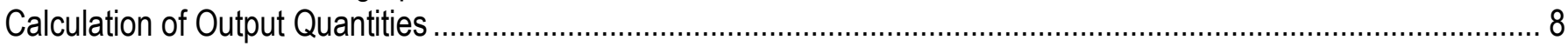

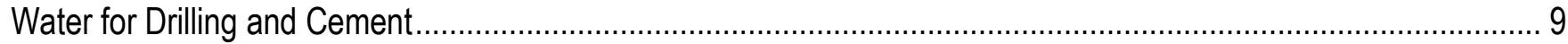

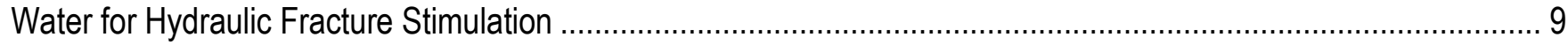

Proppant for Hydraulic Fracture Stimulation ......................................................................................... 9

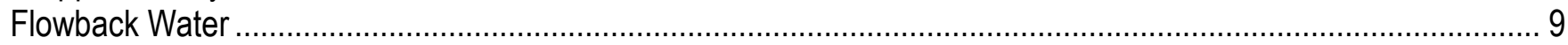

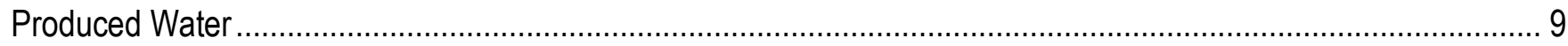

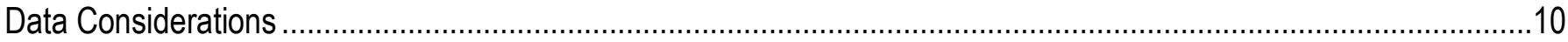

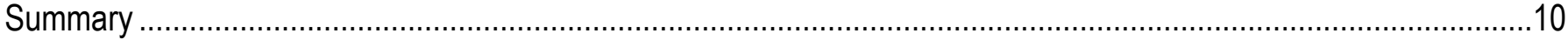

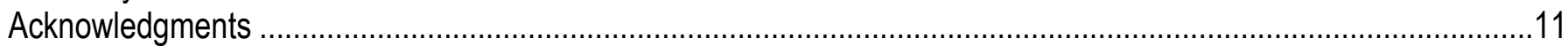

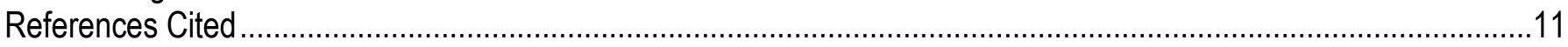

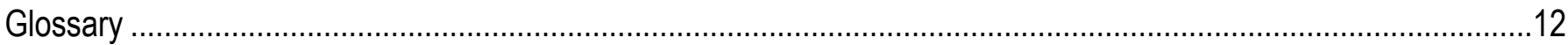

Appendix 1. Input Form for Assessing Quantities of Water and Proppant Injection, and Water Production Associated with Development of Continuous Petroleum Accumulations...........................................................................13

Appendix 2. Monte Carlo Program for Assessing (1) Quantities of Water and Proppant Injection and (2) Water Production Associated with Development of Continuous Petroleum Accumulations ................................................14

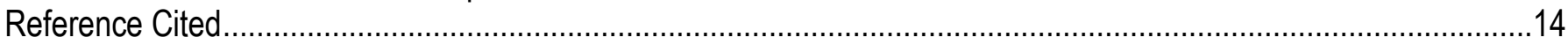

Appendix 3. Estimation of the Water-to-Petroleum Ratio and the Flowback Percent .............................................15

Appendix 4. Letter of Review and Approval from the Committee on Resource Evaluation (CORE) of the American

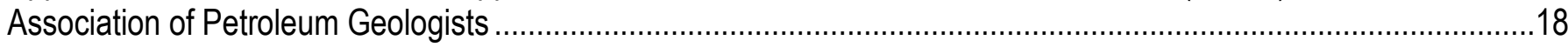

\section{Figures}

3-1. Schematic drawing to illustrate the procedure for calculating the ratio of produced water to produced petroleum.

3-2. Schematic drawing to illustrate the procedure for calculating the percentage of hydraulic fracturing water that returns as flowback for each well in the selected group of wells 


\title{
Methodology for Assessing Quantities of Water and Proppant Injection, and Water Production Associated with Development of Continuous Petroleum Accumulations
}

\author{
By Seth S. Haines
}

\begin{abstract}
The quantities of water and hydraulic fracturing proppant required for producing petroleum (oil, gas, and natural gas liquids) from continuous accumulations, and the quantities of water extracted during petroleum production, can be quantitatively assessed using a probabilistic approach. The water and proppant assessment methodology builds on the U.S. Geological Survey methodology for quantitative assessment of undiscovered technically recoverable petroleum resources in continuous accumulations. The U.S. Geological Survey assessment methodology for continuous petroleum accumulations includes fundamental concepts such as geologically defined assessment units, and probabilistic input values including well-drainage area, sweet- and non-sweet-spot areas, and success ratio within the untested area of each assessment unit. In addition to petroleum-related information, required inputs for the water and proppant assessment methodology include probabilistic estimates of per-well water usage for drilling, cementing, and hydraulic-fracture stimulation; the ratio of proppant to water for hydraulic fracturing; the percentage of hydraulic fracturing water that returns to the surface as flowback; and the ratio of produced water to petroleum over the productive life of each well. Water and proppant assessments combine information from recent or current petroleum assessments with waterand proppant-related input values for the assessment unit being studied, using Monte Carlo simulation, to yield probabilistic estimates of the volume of water for drilling, cementing, and hydraulic fracture stimulation; the quantity of proppant for hydraulic fracture stimulation; and the volumes of water produced as flowback shortly after well completion, and produced over the life of the well.
\end{abstract}

\section{Introduction}

A substantial portion of the current petroleum development in the United States and around the world is focused on "continuous" resources such as petroleum (oil, gas, and natural gas liquids) reservoirs in shale formations, in coal beds, and in low-permeability sandstones and carbonates. Although specific definitions of continuous petroleum accumulations are debated, the U.S. Geological Survey (USGS) has characterized them as "pervasive throughout a large area, ... not significantly affected by hydrodynamic influences, and ... lack[ing] down-dip water contacts" (Klett and others, 2003, pg 1). The oil or gas continuous petroleum accumulations contain is not trapped conventionally by impermeable beds sealing structural or stratigraphic traps, nor was it transported to the accumulation by buoyancy forces. These accumulations are also commonly referred to as "unconventional" resources, and in some but not all cases, the petroleum source rock is also the reservoir. Development of continuous petroleum resources typically involves the use of water for well drilling, cementing, and 
hydraulic fracture stimulation, as well as proppant (often sand) used in hydraulic fracturing to hold the fractures open. Significant quantities of water are often extracted from the well along with petroleum; this produced water includes formation water (usually brackish water or brine), flowback water (water from hydraulic fracturing that returns to the surface), and sometimes also aqueous fluids condensed from the gas phase. Although hydraulic-fracture stimulation may also be used in the production of conventional petroleum accumulations, the methodology described in this document is applicable only to accumulations that fit the USGS definition of "continuous."

The USGS provides periodic appraisals of the Nation's resources, including quantitative assessments of energy resources. The USGS methodology for assessing petroleum in continuous accumulations (Charpentier and Cook, 2010) is geologically based, and it uses a Monte Carlo method to combine probabilistic input data and determine a probabilistic estimate of the quantity of undiscovered, technically recoverable petroleum. This methodology includes several components that are directly relevant to quantitative assessment of water and proppant involved with the production of petroleum from continuous accumulations. Key elements of USGS petroleum assessments include the subsurface drainage area of each petroleum well, estimated ultimate recovery (EUR) of petroleum per well, "sweet spot" and "non-sweet-spot" areas (a distinction based on risk and EUR), and success ratio of wells within each type of area. Sweet spots are the area(s) of the AU that are more favorable to yielding higher-EUR petroleum wells. Each USGS assessment of continuous petroleum is based on extensive geologic research and analysis of well-production data, and the assessment calculations include quantification of the number of wells potentially associated with developing the petroleum resource.

This report presents a methodology for quantitative probabilistic assessment of the quantities of water and proppant potentially required for producing petroleum from continuous accumulations, as well as the quantities of water extracted during petroleum production. This methodology incorporates available data regarding water and proppant usage and regarding water production for areas being assessed. The methodology also draws on key concepts from the USGS continuous petroleum assessment methodology and on data from individual petroleum assessments to obtain water and proppant-assessment results that are consistent with corresponding USGS petroleum assessments and that are directly linked to the underlying geology. A fundamental characteristic of USGS water and proppant assessments is that they represent an assessment of resource requirements and resource coproduction; that is, assessments represent the requirement for and(or) production of one resource as related to development of another resource. This is a distinction from USGS petroleum assessments, which estimate the quantity of a single resource. These assessments for water and proppant are designed to address emerging questions regarding the water-related effects of oil and gas production irrespective of policy choices, economics, or other factors that could effect future petroleum development.

This document reviews USGS assessments of continuous petroleum accumulations and describes some key aspects of these assessments. It then describes the objectives and procedure for assessing water and proppant related to petroleum development and the necessary input information. It discusses the procedure for determining input values for each assessment, important considerations regarding the assessment input data, and water and proppant assessments as a whole. Lastly, it provides the assessment input form and the Monte Carlo program that are used in these assessments.

\section{Background: USGS Petroleum Assessments}

\section{Overview}

Charpentier and Cook (2010) describe the USGS methodology for quantitative assessment of continuous petroleum resources. The approach incorporates geologic and well production data to 
determine a probabilistic estimate of the undiscovered, technically recoverable, petroleum resource (including oil, gas, and natural gas liquids) in each geologically defined assessment unit (AU). An AU represents the specific volume of rock to which an assessment corresponds; AUs are the smallest explicit spatial subdivisions that can be made in an area being assessed, based on available geologic and geophysical information. Each AU is viewed as being part of a total petroleum system (TPS) that includes all of the elements necessary for the presence of recoverable petroleum resources (Charpentier and Cook, 2010; Schmoker, 2005). To conduct an assessment, the assessment team estimates input values for each AU, including: (1) the minimum estimated ultimate recovery (EUR) of petroleum that is necessary for a well to be considered successful, (2) the spatial area of the AU, (3) the subsurface drainage area of the wells, (4) the percent of the AU area that is untested, (5) the percent of the untested area that is "sweet spot" (lower risk and generally higher EUR than "non-sweet spot" areas), (6) the success ratios of possible wells in both sweet- and non-sweet-spot areas, and (7) the EUR for successful wells in both sweet- and non-sweet-spot areas. Each input value other than the minimum EUR is defined not as a single value, but as a probability distribution that describes the relative probabilities of possible values. These input probability distributions are estimated based on geologic, geophysical, geochemical, and petroleum-production data from the AU area, or from analogous areas. Any existing wells within the AU that target the stratigraphic interval of interest represent area that is "tested"; the assessment estimates the quantity of undiscovered petroleum in the untested area. In these assessments, potential future wells are considered "successful" if they are expected to yield at least 2,000 barrels of oil (for continuous oil accumulations) or 0.02 billion cubic feet of gas (for continuous gas accumulations); these quantities do not necessarily reflect economic or other considerations that would effect development practices. The input data are combined in a Monte Carlo simulation (Charpentier and Cook, 2010) that determines the total undiscovered technically recoverable petroleum in the AU, as a probability distribution that conveys the distribution of possible volumes.

\section{Key Quantities}

USGS assessments of continuous petroleum resources estimate the technically recoverable resource based on geologic and well production information. The procedure includes, as an intermediate step, calculation of the number of wells potentially associated with this undiscovered resource. The well count is calculated separately for sweet and non-sweet spots, and the calculation draws on the untested area of the AU, the percent of the untested area that lies within sweet spots, and the drainage area of each well. As such, these inputs for the petroleum assessment also represent critical quantities for water and proppant assessment, as they provide well count estimates that are directly tied to the geologic and well production information in the USGS petroleum assessment.

The number of wells associated with the assessed petroleum resource is typically large (ranging from hundreds to hundreds of thousands) and thus it is the uncertainty of the mean value of each input distribution that relates to the uncertainty in the output distributions, as discussed by Charpentier and Cook (2010). Accordingly, the uncertainty inherent in the inputs is addressed by specification of the distribution of subjective uncertainty of the mean. As subjective uncertainty distributions, these do not necessarily have a defined form (such as normal or lognormal). As a simplification, triangular distributions are used for most inputs, and shifted truncated lognormal distributions are used for EUR because it is expected to be heavily right-skewed, as described by Charpentier and Cook (2010). 


\section{Water and Proppant Assessments}

\section{Objectives}

The assessment methodology described in this document provides a probabilistic estimate of the water and proppant potentially required for development of continuous petroleum resources, and the water that will potentially be produced with the petroleum resource. These water and proppant assessments are conducted for AUs defined in the course of USGS petroleum assessments and build from the associated geologic and well production studies to maintain institutional consistency. Each water and proppant assessment requires estimation of a number of input values that describe various quantities related to water and proppant requirements and water production per well. In addition, each water and proppant assessment incorporates input information drawn from the most recent USGS continuous petroleum assessment for that area.

\section{Procedure}

The first step in conducting an assessment of water and proppant, according to the methodology described herein, is to determine whether the area of interest is suitable for such an assessment. These assessments can only be conducted for AUs for which a USGS continuous petroleum assessment has been carried out sufficiently recently that the petroleum assessment assumptions, input data, and results remain relevant. For each AU being studied, the assessment of water and petroleum requires compilation and analysis of water- and proppant-related data to determine the necessary input values. In addition, the assessor must consider the input and output values of the continuous petroleum assessment for the $\mathrm{AU}(\mathrm{s})$ being studied, and their implications regarding water and proppant usage and water production. The assessor assembles a draft input sheet for each AU being assessed. The water and proppant assessment team meets to review the input values for each AU and to discuss any necessary changes. Upon determination of final input values for each AU, the input values are loaded into the @ Risk spreadsheet (included as Appendix 2 of this document) and the assessment computations are carried out.

\section{Assessment Considerations and Presentation of Results}

USGS petroleum assessments consider the undiscovered, technically recoverable resource in each AU. By design, these assessments do not include any indication of the timeframe over which this resource could be produced, nor any indication of whether it will be produced at all. Accordingly, quantities of water and proppant assessed according to the methodology described herein correspond with the entire undiscovered technically recoverable petroleum resource without any suggestion of the timing or rate of water/proppant requirement or water production.

Many questions relating to water and proppant supply, and water disposal are directly tied to the rate of the resource requirement or production and thus to the rate of petroleum production. Many other water-related questions relate to the specific source of water used for petroleum production (surface water, groundwater, or other sources, and also the particular location of extraction). Similarly, many water production questions relate to the fate of the produced water-whether it is disposed of by deep injection, treated for surface disposal, or reused for further petroleum production. The reuse of produced water of course has implications regarding both water sourcing and water disposal.

Future petroleum development rates, the specific sources of water and proppant for possible future petroleum development, and the fate of future produced water are all unknown. Similarly, the quantity (if any) of produced water that will be reused in future petroleum production is also unknown. 
Accordingly, the described methodology quantifies only fundamental information: the gross quantities of (1) water for drilling and cement, (2) water for hydraulic fracturing, (3) proppant for hydraulic fracturing, (4) water produced as flowback, and (5) produced water. This information is aimed to provide information that is relevant and useful for supply and disposal questions but that does not overstep the bounds of what is scientifically valid.

To augment the fundamental assessment information, a suite of auxiliary information is presented along with the main assessment results as described by Haines and others (2014). This auxiliary information, which includes data about existing petroleum production and the local hydrogeologic system, is intended to provide context and relevance for the main assessment information; it is not directly part of the probabilistic assessment methodology but it is key to the presentation of the fundamental assessment information. Because specific statements regarding future events are inherently speculative, the assessments cannot predict rates of petroleum production or water use/production. However the numbers of wells drilled in recent years, and estimates of the potential water volumes associated with various drilling rates, can help answer questions involving potential future petroleum production and associated water requirements and production. Information regarding water volumes associated with the broader hydrologic system (surface water and groundwater withdrawals, precipitation, and water usage for various usage categories) aim to inform questions regarding water sourcing and disposal, and to provide context for the assessed quantities. These numbers represent the fundamental elements of a simple water budget for the area of study (Healy and others, 2007; Haines and others, 2014).

\section{Assessment Input Data Form}

The input values used in the assessment are recorded in a standardized input form (Appendix 1). The form includes the general identification information for the AU, information drawn from the USGS petroleum assessment to which the water/proppant assessment corresponds, and estimates of water and proppant injection and production quantities required for the assessment. In addition, the input form contains the data that are used to provide context for the fundamental assessment results. Finally, the input form includes additional data related to petroleum development practices, water usage, and water properties.

\section{Identification Information}

The first section of the input form includes various general identification information. This includes information regarding the AU within the context of the USGS classification scheme involving the province, petroleum system, and other information, as described by Klett and others (2003). It also includes information on the assessment being carried out, including the date of the assessment meeting, the lead scientist, the assessment team, and the associated USGS petroleum assessment for the same area, following Charpentier and Cook (2010).

\section{Information from the Associated Petroleum Assessment}

The second section of the input form contains fundamental geologic and petroleum-related information for the AU, including characteristics of past production, and criteria regarding possible future wells considered successful, as described by Charpentier and Cook (2010). The number of undrilled wells with potential for additions to reserves is a key value for water and proppant assessments. The input values in lines 1-4 are the estimated ranges of the productive area of the accumulation, drainage area for each well, untested area, and proportion of the AU area that lies within 
sweet spots. These input values allow calculation of the likely number of undrilled wells with potential for additions to reserves, which is a key value for water and proppant assessments. Details regarding these input values are described by Charpentier and Cook (2010). All of the information entered into this section of the input form is drawn directly from the associated petroleum assessment so that the well counts and other geologically based aspects match those in the corresponding petroleum assessment. Much of the information in this section is used directly in the water/proppant assessment, and the rest is included for completeness.

\section{Injection and Production Per Well}

Distributions indicating the estimated injection volumes and productivities of wells in the untested area are entered in lines $5 \mathrm{a}$ through $6 \mathrm{i}$. They are in two sets: lines 5a through $5 \mathrm{i}$ are for sweet spot areas and lines $6 \mathrm{a}$ and $6 \mathrm{i}$ are for non-sweet spot areas.

A distribution representing the future success ratio within sweet spots is entered in line $5 \mathrm{a}$ and the future success ratio for non-sweet spots is entered in line 6a. This success ratio is the percent of potential drilling sites that could yield at least the minimum EUR. A distribution representing the average EUR of possible future successful wells in the untested sweet spot area is provided in line 5i, and the average EUR in the untested non-sweet spot area is entered in line 6i. Future success ratio and EUR are described in greater detail by Charpentier and Cook (2010), and the values used for these inputs (lines 5a, 5i, 6a, and 6i) are drawn directly from the underlying petroleum assessment.

The percentage of unsuccessful wells that are drilled, cemented, and hydraulically fractured is indicated for sweet spots by the distribution on line $5 \mathrm{~b}$ and for non-sweet spots by the distribution on line $6 \mathrm{~b}$. This value is used to account for wells that do not produce at least the specified minimum EUR (and thus are not part of the USGS petroleum assessment) but which do require water and proppant and which yield flowback water. This value is estimated based on geologic and well production concepts and trends in the study area, on the success ratios for sweet and non-sweet spots in the AU, and on any available information regarding the distinction between successful and non-successful wells.

The input distributions on lines $5 \mathrm{c}$ through $5 \mathrm{f}$ and $6 \mathrm{c}$ through $6 \mathrm{f}$ describe the per-well proppant and water potentially required for future wells in the AU; these inputs are all expressed as subjective uncertainties of a mean value. The average volume of water used per well for drilling, cementing, and associated processes is indicated for sweet spots by the distribution on line $5 \mathrm{c}$ and for non-sweet spots by the distribution on line $6 \mathrm{c}$, in units of gallons. The average volume of water used per treatment for hydraulic fracture stimulation is indicated for sweet spots by the distribution on line $5 \mathrm{~d}$ and for nonsweet spots by the distribution on line $6 \mathrm{~d}$, in gallons. The average number of hydraulic fracture treatments per well is indicated for sweet spots by the distribution on line 5e and for non-sweet spots by the distribution on line 6e; this input allows the assessor to indicate prevailing trends in the AU. Values less than one indicate that not all wells receive hydraulic fracturing treatments, while values greater than one indicate multiple treatments per well. It is important that publications of assessment results state clearly the implications of the chosen values for lines 5e and 6e, including the timeframe over which multiple treatments are expected to occur. The average ratio of proppant to water for hydraulic fracture stimulation is indicated for sweet spots by the distribution on line $5 \mathrm{f}$ and for non-sweet spots by the distribution on line 6f, in units of pounds of proppant per gallon of water. Proppant quantity is specified relative to water volume in recognition of the physical limitations controlling the quantity of proppant that can be carried by a given volume of hydraulic fracturing fluid; different types of fluid (gel versus slickwater for example) will show different proppant-to-water ratios. The input distributions on lines 5c through $5 \mathrm{f}$ and $6 \mathrm{c}$ through $6 \mathrm{f}$ are determined through analysis of relevant recent data for the AU being studied, or determined through analysis of data for areas deemed analogous and consideration of drilling 
and completion practices. For example, the predominant type of hydraulic fracturing fluid, the length of the lateral, and the portion of the well that is cemented are key considerations regarding these values. The input values on lines $5 \mathrm{c}$ through $5 \mathrm{f}$ (sweet spot areas) may be the same as those on lines $6 \mathrm{c}$ through 6f (non-sweet-spot areas), and in fact this may often be the case.

The input distributions on lines $5 \mathrm{~g}, 5 \mathrm{~h}, 6 \mathrm{~g}$, and $6 \mathrm{~h}$ describe the per-well water production, divided into two parts; these inputs are all expressed as subjective uncertainties of a mean value. The average percentage of the water volume injected during hydraulic fracturing that returns to the surface as flowback water (as defined earlier in this document) is indicated for sweet spots by the distribution on line $5 \mathrm{~g}$ and for non-sweet spots by the distribution on line $6 \mathrm{~g}$. This distribution can be determined from recent water and petroleum production data for each well according to the procedure described in Appendix 3. The value may be the same for sweet- and non-sweet-spot areas. The average long-term ratio of water to petroleum (discounting flowback water) is indicated for sweet spots by the distribution on line $5 \mathrm{~h}$ and for non-sweet spots by the distribution on line $6 \mathrm{~h}$. This distribution can be determined through analysis of water and petroleum production data, as described in Appendix 3. For oil, the ratio is a unitless value representing the volumetric ratio of water to oil. For gas, the ratio is expressed in units of gallons of water per thousand cubic feet of gas (mcfg). Although this value too may be the same for sweet- and non-sweet-spot areas, it is expected that generally sweet- and non-sweet-spot areas will exhibit different characteristics.

Because hundreds to thousands of thousands of wells may be involved in the assessment calculations, only the mean value is computationally relevant for the inputs on lines $5 \mathrm{c}$ through $5 \mathrm{i}$, and 6c through 6i; accordingly, each of these inputs specifies the subjective uncertainty of the mean value, following Charpentier and Cook (2010). Being subjective uncertainty distributions, these do not necessarily have a specified form; for simplicity triangular distributions are used for inputs on lines 5a through $5 \mathrm{~h}$ and $6 \mathrm{a}$ through $6 \mathrm{~h}$. The EUR distributions (lines $5 \mathrm{i}$ and $6 \mathrm{i}$ ) are generally expected to be heavily right skewed, so shifted truncated lognormal distributions are used (Charpentier and Cook, 2010). As noted earlier, the inputs on lines 5a, 5i, 6a, and 6i are drawn directly from the associated petroleum assessment.

\section{Ancillary Data}

In addition to the fundamental assessment inputs, the Input Form includes additional information regarding the regional hydrological system and petroleum drilling practices in the "Ancillary Data" section. The section includes water-related data that are necessary for calculation of the hydrological information presented along with the assessment outputs to provide context, including volumes describing surface water and groundwater, water usage, and precipitation (as described by Haines and others, 2014). The water volumes entered into the Ancillary Data section of the Input Form refer specifically to the AU in question; however, the assessor may make note in this section and in any associated publications if there exist nearby, but outside of the AU boundaries, significant water entities that are relevant to the water supply in the area. This section also contains information regarding recent well-drilling activities along with typical completion practices. In addition, the ancillary data includes typical characteristics (for example, basic chemical characteristics) of produced waters in the AU and space to provide any other information deemed relevant and potentially useful.

\section{Allocations to other Geographic Entities}

Some users of probabilistic resource assessment information will encounter questions or concerns regarding the spatial scale and the spatial specificity (or lack-thereof) of the assessment; they are likely to be interested in probable specific locations of the assessed petroleum production, required 
water for injection, and water production. To address some of these needs, estimates of the various assessed quantities allocated among different spatial entities (including states, counties, and hydrologic units) are provided. The specific entities provided for a given AU will depend on what is relevant in that area, and the assessed quantities to be allocated may also vary between assessments. As such, the Input Form contains a general section where these allocations may be indicated; the specific entries in the section are to be adjusted as necessary for each assessment. Calculation of the allocated quantities is based on the mean values of each probabilistic assessed quantity, rather than full distributions, because these quantities can much more readily be accurately determined (Charpentier and Cook, 2010). The allocation values are generally determined by simple percent-area partitioning, unless compelling information exists to indicate anything other than spatially uniform distribution of the petroleum resource and petroleum development.

\section{Calculation of Output Quantities}

Two distinct numbers of wells ("well counts") are involved in calculation of the water and proppant output quantities. Whereas USGS assessments of continuous petroleum calculate the total undiscovered resource based on the number of undrilled wells that have potential for addition to reserves ("successful wells"), assessments of the associated water and proppant must, in addition, include any unsuccessful wells that would potentially be drilled and completed (cemented, perforated, and hydraulically fractured). The number of successful wells is calculated based on the AU area, the percent of the AU that lies within sweet spots, the well drainage area, and the sweet-spot and non-sweet spot success ratios, as described by Charpentier and Cook (2010). The number of unsuccessful wells in the AU that are drilled and completed is calculated by multiplying together the input "percentage of unsuccessful wells that are drilled and completed" and the total number of unsuccessful wells. The total number of drilled and completed wells (successful and unsuccessful) is used in calculating water and proppant requirements, and the flowback water volume. Only the number of successful wells in the AU is included when calculating the total volume of produced water for the life of the well.

Several of the input values are correlated with one another, and these correlations must be accounted for to yield accurate results. In particular, several inputs are correlated with the drainage area: (1) the EUR, (2) the per-well water for drilling and cement, and (3) the per-well water for hydraulic fracturing. The water quantities for drilling, cement, and hydraulic fracturing are all correlated with the length of the horizontal part of the borehole (the lateral length); the lateral length is not directly specified among the assessment inputs, but it is one of many factors effecting the well drainage area.

We use a value of 0.5 for the correlation of EUR with drainage area to maintain consistency with USGS continuous petroleum assessments (Charpentier and Cook, 2010). We determine the other correlation values through expert elicitation, following Blondes and others (2013a, 2013b), and establish a correlation matrix that is mathematically self-consistent. We use a value of 0.5 for the correlation of drilling/cement water with drainage area, and for the correlation of hydraulic fracturing water with drainage area; the correlation coefficient 0.5 indicates moderate correlation between two variables. Because EUR, drilling/cement water volume, and hydraulic fracturing water volume are all correlated with the drainage area, they must show at least some correlation with each other. Accordingly, we include correlation values of 0.15 (indicating very low, but non-zero, correlation) for drilling/cement water with EUR and hydraulic fracturing water with EUR. We include a value of 0.5 for the correlation of drilling/cement water with hydraulic fracturing water, indicating the moderate correlation between these volumes due to the close relationship of each to the lateral length/drainage area. Each of these inputs (EUR, drilling/cement water, and hydraulic fracturing water) are defined separately for sweet and non-sweet spots, so the correlations are defined for each set of inputs. We do not include correlation 
between sweet- and non-sweet-spot water volumes or EUR, beyond what is implied by the inclusion of correlation between each individual input value and the drainage area.

\section{Water for Drilling and Cement}

The total water for drilling and cement is determined separately for sweet-spot areas and nonsweet-spot areas by multiplying the number of drilled and completed wells (successful and unsuccessful) by the per-well volume of water for drilling and cementing. Each of these values is a probability distribution, and the calculation is carried out with a Monte Carlo approach. The sweet spot and non-sweet spot quantities are summed to provide the total for the AU.

\section{Water for Hydraulic Fracture Stimulation}

The total water for hydraulic-fracture stimulation is determined separately for sweet-spot areas and non-sweet-spot areas by multiplying the number of drilled and completed wells (successful and unsuccessful) by the per-well volume of water for hydraulic fracturing and by the number of hydraulic fracturing treatments per well. Each of these values is a probability distribution, and the calculation is carried out with a Monte Carlo approach. The sweet spot and non-sweet spot quantities are summed to provide the total for the AU.

\section{Proppant for Hydraulic Fracture Stimulation}

The total proppant for hydraulic-fracture stimulation is determined separately for sweet-spot areas and non-sweet-spot areas by multiplying together the number of drilled and completed wells (successful and unsuccessful), the ratio of proppant quantity to water volume, the per-well volume of water for hydraulic fracturing, and the number of hydraulic fracturing treatments per well. Each of these values is a probability distribution, and the calculation is carried out with a Monte Carlo approach. The sweet spot and non-sweet spot quantities are summed to provide the total for the AU.

\section{Flowback Water}

Total flowback water is determined separately for sweet-spot areas and non-sweet-spot areas by multiplying together the number of drilled/completed wells (successful and unsuccessful), the percentage of hydraulic fracturing water that returns to the surface as flowback water, the per-well volume of water for hydraulic fracturing, and the number of hydraulic fracturing treatments per well. These values are all specified as probability distributions and the calculation is carried out in a Monte Carlo approach. The sweet spot and non-sweet spot quantities are summed to provide the total for the AU.

\section{Produced Water}

The non-flowback-produced water is determined separately for sweet-spot areas and non-sweetspot areas by multiplying together the number of successful wells, the EUR for wells in the AU, and the water-to-petroleum ratio for wells in the AU. These values are probability distributions and the calculation is carried out with a Monte Carlo approach. The total produced water for the AU is then determined by summing together the non-flowback produced water and the flowback water volumes for sweet-spot and non-sweet-spot areas. 


\section{Data Considerations}

As described in the previous sections, assessment input values that correspond directly to values in the continuous petroleum assessment for the study area are drawn verbatim from that petroleum assessment. The water- and proppant-related values are estimated based on the best and most relevant available data. In general, it is preferable to estimate assessment input values based on geologic, well production, and other data specific to the AU being studied. Some AUs, however, may not be extensively developed and some may even be entirely hypothetical; in these cases, the input data must be derived by comparison with geologic and production data for areas with similar subsurface characteristics ("analogs"). In addition, there may be maturely developed AUs for which the available data are not sufficient for robust estimation of all of the necessary input values; in these cases, data from analog areas may also be used.

The purpose of a probabilistic assessment method is to determine a best possible estimate of the quantity being assessed, given the specified uncertainties in the input values; this can only be reasonably accomplished with adequate data. For areas where insufficient data exist, and(or) where reasonable analog data are not available, uncertainties might be so broad as to render assessment results nonhelpful. In other areas, available data may be better for some parts of the assessment than for others. For example, it could be possible to conduct a robust and useful assessment for water and proppant requirements and flowback production using analog data, whereas estimating the total produced water volume might include excessive uncertainty without local production data.

Production practices play a key role in water and proppant usage, and potentially also in water production. Changes in these practices will result in changes in water and proppant usage and water production, just production practices can also effect the EUR. All assessments are conducted using the best available information, but substantial changes in production practice generally cannot be foreseen. As such, the results of these water and proppant assessments are linked to a particular set of production practices, and significant changes could make the assessment results obsolete, as is also the case for assessments of undiscovered petroleum.

\section{Summary}

The described methodology enables assessment of five quantities associated with the development of undiscovered, technically recoverable continuous petroleum accumulations: (1) the quantity of water for drilling and cementing, (2) the quantity of water for hydraulic fracture stimulation, (3) the quantity of proppant for hydraulic fracture stimulation, (4) the quantity of flowback water, and (5) the quantity of produced water. The assessment methodology is linked to the USGS methodology for assessing continuous petroleum resources, and each individual water and proppant assessment is linked directly to the most recent USGS continuous petroleum assessment for that area. Each water and proppant assessment incorporates probabilistic estimates of input values describing water and proppant usage and water production associated with petroleum production, along with data from the USGS petroleum assessment, in a Monte Carlo approach, to estimate the probabilistic output quantities. The methodology has been designed to ensure robust, geologically based estimates of water and proppant quantities and to avoid speculation regarding specific future activities and effects. The objective of the methodology is to provide unbiased information that helps a wide range of end-users understand the quantities of water and proppant potentially involved with the production of undiscovered technically recoverable petroleum resources. 


\section{Acknowledgments}

Many individuals contributed to this work in a variety of ways. Ron Charpentier and Troy Cook provided considerable guidance and suggestions that have been essential to the development of this methodology. Ron Charpentier has been a key collaborator throughout the process. Sarah Hawkins and Mark Engle have participated in many helpful discussions on these topics. Brian Varela has conducted extensive analyses of drilling and production data, which are critical to understanding the underlying processes and their relation to assessments. Madalyn Blondes contributed valuable suggestions regarding correlation matrixes. Joanna Thamke, Rick Healey, Andy Long, Kyle Davis, and Bruce Smith have been a key collaborators on many topics, including the linking of assessment outputs to regional water systems. Lynn Tennyson provided valuable comments on this manuscript. And the input of AAPG's Committee on Resource Evaluation (CORE) has provided valuable input that has improved the methodology and the document.

\section{References Cited}

Blondes, M.S., Brennan, S.T., Merrill, M.D., Buursink, M.L., Warwick, P.D., Cahan, S.M., Cook, T.A., Corum, M.D., Craddock, W.H., DeVera, C.A, Drake, R.M., II, Drew, L.J., Freeman, P.A., Lohr, C.D., Olea, R.A., Roberts-Ashby, T.L., Slucher, E.R., and Varela, B.A., 2013a, National assessment of geologic carbon dioxide storage resources-Methodology implementation: U.S. Geological Survey Open-File Report 2013-1055, 26 p., http://pubs.usgs.gov/of/2013/1055/.

Blondes, M.S., Schuenemeyer, J.H., Olea, R.A., and Drew, L.J., 2013b, Aggregation of carbon dioxide sequestration storage assessment units: Stochastic Environmental Research and Risk Assessment, v. 27, no. 8, 1839-1859.

Charpentier, R.R., and Cook, T.A., 2010, Improved USGS methodology for assessing continuous petroleum resources: U.S. Geological Survey Data Series 547, 22 p. and program, http://pubs.usgs.gov/ds/547/.

Haines, S.S., Cook, T.A., Thamke, J.N., Davis, K.W., Long, A.J., Healy, R.W., Hawkins, S.J., and Engle, M.A., 2014, A framework for assessing water and proppant use and flowback water extraction associated with development of continuous petroleum resources: U.S. Geological Survey 2014-3010, 6 p., http://dx.doi.org/10.3133/fs20143010.

Healy, R.W., Winter, T.C., LaBaugh, J.W., and Franke, O.L., 2007, Water budgets-Foundations for effective water-resources and environmental management: U.S. Geological Survey Circular 1308, $90 \mathrm{p}$.

Klett, T.R., Schmoker, J.W., Charpentier, R.R., Ahlbrandt, T.S., and Ulmishek, G.F., 2003, Glossary, chap. 25 of U.S. Geological Survey Uinta-Piceance Assessment Team, Petroleum Systems and Geologic Assessment of Oil and Gas in the Uinta-Piceance Province, Utah and Colorado: U.S. Geological Survey Digital Data Series DDS-69-B, 3 p., http://pubs.usgs.gov/dds/dds-069/dds-069-b/.

Schmoker, J.W., 2005, U.S. Geological Survey assessment concepts for continuous petroleum accumulations, chap. 13 of U.S. Geological Survey Southwestern Wyoming Assessment Team, Petroleum systems and geologic assessment of oil and gas in the southwestern Wyoming province, Wyoming, Colorado, and Utah: U.S. Geological Survey Digital Data Series DDS-69-D, http://pubs.usgs.gov/dds/dds-069/dds-069-d/reports.html. 


\section{Glossary}

Assessment unit The specific volume of rock to which a U.S. Geological Survey petroleum assessment relates. The assessment unit (AU) is defined based on geologic, geophysical, and geochemical data. Within each AU, all assessment information is defined probabilistically. Fundamental to the definition of the AU is the concept that the specific location of petroleum within the AU is unknown. For more information, refer to Klett and others (2003) and Schmoker (2005).

Completion The procedures used to prepare a drilled petroleum well to enable production from that well. We use the term to include cementing and perforation of the well casing, stimulation treatments such as hydraulic fracturing, and insertion of production tubing.

Continuous petroleum resources Petroleum accumulations, such as shale oil or gas, coalbed natural gas, and tight oil or gas, that are not held in place by seals, geologic traps, or the buoyancy of oil and gas relative to water. For more information, refer to Klett and others (2003) and Schmoker (2005).

Flowback water Water injected during hydraulic fracturing that is extracted during petroleum production, mainly during the first several weeks or months after hydraulic fracturing. In produced water samples, it is difficult to distinguish between flowback water and formation brine, so for assessment purposes, we define flowback water as the volume of water that exceeds the baseline water/petroleum production ratio (determined through analysis of well production data as described in Appendix 3).

Formation brine/water Water, generally of brackish water or brine, that occurs naturally in geologic formations; the term is most often applied to water in petroleum reservoirs.

Produced water Any water that flows out of a well during petroleum production; this includes flowback water, formation brine, and sometimes also aqueous fluids condensed from the gas phase. Produced water may also be called "co-produced water."

Proppant Granular material, typically sand, used to hold open fractures created during hydraulic fracture stimulation.

Technically recoverable Resources in accumulations that are producible using current recovery technology, without reference to economic profitability.

Total petroleum system (TPS) A geologic system containing all of the necessary elements for technically recoverable petroleum: source, reservoir, and seal, as well as the processes of generation, migration, entrapment, and preservation of oil, natural gas, and natural gas liquids. The concept of the TPS underlies all USGS petroleum assessments. For more information, refer to Klett and others (2003). 


\begin{abstract}
Appendix 1. Input Form for Assessing Quantities of Water and Proppant Injection, and Water Production Associated with Development of Continuous Petroleum Accumulations
\end{abstract}




\section{Appendix 2. Monte Carlo Program for Assessing (1) Quantities of Water and Proppant Injection and (2) Water Production Associated with Development of Continuous Petroleum Accumulations}

The described assessment methodology relies on Monte Carlo simulation to combine the probabilistic input values and determine probabilistic output values. This computation is performed with @ Risk software (Palisade, 2014), using the attached workbook

(Continuous_water_proppant_2014.xlsm). @Risk software runs within Microsoft Excel, and use of Continuous_water_proppant_2014.xlsm requires installation of both software packages.

The user of Continuous_water_proppant_2014.xlsm is advised to enter all assessment input values into the "Main" spreadsheet, to set a number of Monte Carlo simulations that is appropriate for the input distributions and for the desired output accuracy, and to consult the @Risk manual for questions involving use of that software. The "Output_Plots" spreadsheet provides a set of plots that may be helpful for the user, and the "Input_Template" provides a clean display of the input values without the other content that is in the "Main" spreadsheet.

Although this program has been used by the USGS, no warranty, expressed or implied, is made by the USGS or the United States Government as to the accuracy and functioning of the program and related program material nor shall the fact of distribution constitute any such warranty, and no responsibility is assumed by the USGS in connection therewith.

\section{Reference Cited}

Palisade, 2014, @Risk software, version 6.3: Palisade Corporation, Ithaca, New York, available at http://www.palisade.com 


\section{Appendix 3. Estimation of the Water-to-Petroleum Ratio and the Flowback Percent}

The water-to-petroleum ratio (expressed as a probability distribution) is an assessment input that is used in calculation of the total volume of produced water; it can be determined through analysis of historical well production data. For oil AUs, the ratio is a unitless number representing the volume of water per volume of oil, and for gas AUs it is expressed in units of gallons of water per thousand cubic feet of gas (gal/Mcf).

To determine the petroleum/water ratio, the assessor compiles month-by-month production data for the AU or selected analog area, for a minimum of one year of production history. The ratio of water to petroleum is calculated for each month of production for the life of each well. These data are plotted together for all wells deemed relevant to the analysis. As plotted, the horizontal axis represents time incremented by month beginning with the first month of production for each well and the vertical axis represents the water-to-petroleum ratio (fig. 3-1). Wells that have been hydraulically fractured typically show a relatively high water-to-petroleum ratio for the first month of production, and this ratio decreases rapidly over the subsequent two to five months before reaching a stable ratio that persists over time. This stable ratio is referred to as the "baseline production ratio," and it is interpreted to represent formation water that is extracted from the well. For the purposes of our assessments, the water-topetroleum ratio input value is estimated from analysis of the baseline ratios calculated for the group of selected wells. Each study requires analysis of water-to-petroleum production ratios for real production data over long periods of time. For cases where the well data do not show a stable baseline water-topetroleum ratio, the determination of the water-to-petroleum input value may require more complex analyses. 


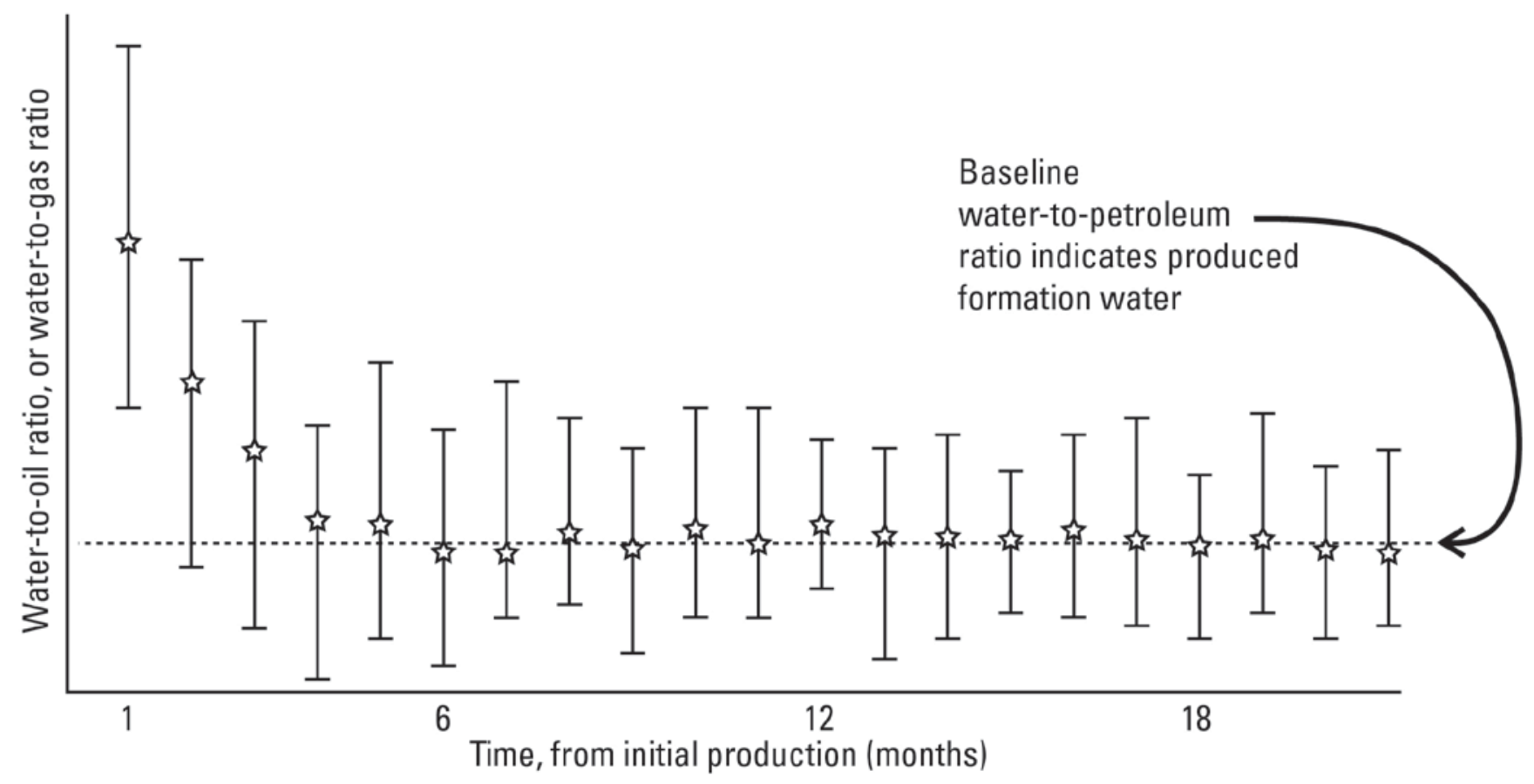

Figure 3-1. Schematic drawing to illustrate the procedure for calculating the ratio of produced water to produced petroleum. Plot represents data from a group of wells, with the ratio of water to petroleum plotted for each month relative to the first month of production for each well. Stars represent the median of the distribution of ratios and the vertical "whiskers" represent the quartiles of the distributions.

The percentage of hydraulic fracturing water that returns to the surface as flowback can be estimated through analysis (fig. 3-2) related to the data-compilation process described above. For each individual well in the selected group of wells, a baseline water-to-petroleum ratio is estimated based on the median of the ratios for production from month 6 through month 12 (or whatever time span is deemed most reliable for the study area). The use of the median, as opposed to the mean, helps to avoid problems associated with outliers related to data errors or other issues. The baseline ratio is assumed to represent formation water, and water that exceeds the baseline ratio is assumed to represent injected water that returns to the surface as flowback. The volume of water produced from the well during the early months of production (5 months or fewer, depending on the area) that exceeds this ratio is calculated and is considered to be flowback water. This flowback volume is determined for each well, and the flowback percent is determined by dividing the estimated flowback volume by the volume of water used for initial hydraulic fracturing of the well. Specific aspects of this procedure may be adjusted as necessary, based on analysis of the available data, to provide the best estimate of flowback percent for each well in the study area. Finally, the distribution of these estimated flowback percentages is analyzed to determine the input value to be used in the assessment. 


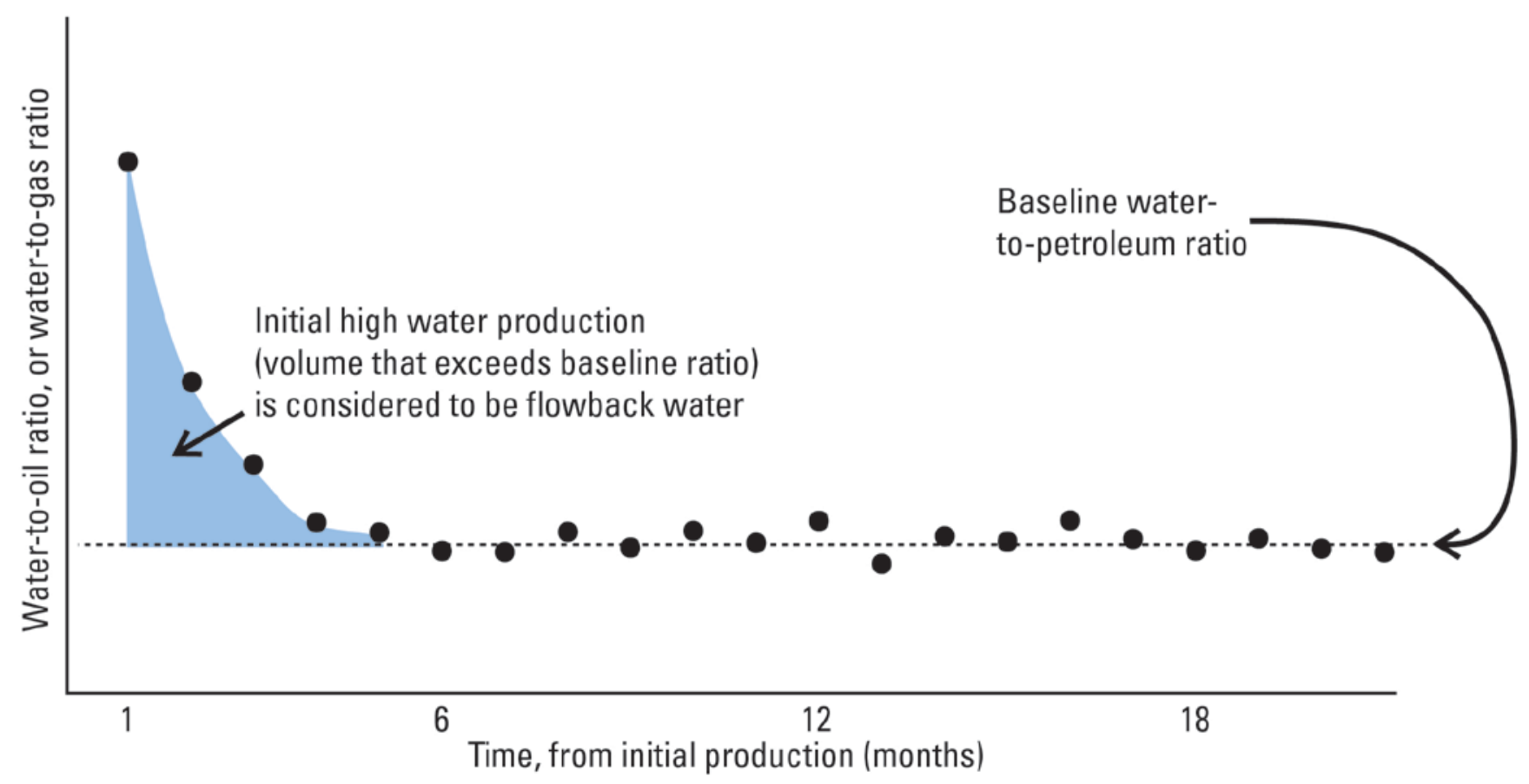

Figure 3-2. Schematic drawing to illustrate the procedure for calculating the percentage of hydraulic fracturing water that returns as flowback for each well in the selected group of wells. Large black dots represent the month-by-month production ratio (water-to-oil, or water-to-gas).

All data require quality analysis and quality control, and in particular, production data warrant careful attention. Because the procedures described in this section rely on ratios of water to petroleum production volumes, these analyses are susceptible to problems in one or the other of the two production volumes (for example, an erroneously low petroleum production value will result in an unreasonably high ratio). As such, we conduct extensive quality control prior to analysis of production data; this includes rejection of values substantially smaller than surrounding values, and rejection of entire wells that show excessive missing data. 
Appendix 4. Letter of Review and Approval from the Committee on Resource Evaluation (CORE) of the American Association of Petroleum Geologists. 